\title{
Knowledge about Factors Associated with Cervical Cancer in Women: A Cross Sectional Study, Dhaka, Bangladesh
}

\author{
Dr. Taslima Nigar ${ }^{1 *}$, Md. Monirul Hassan ${ }^{2}$
}

\author{
${ }^{1}$ Junior Consultant, Department of Gynaecological oncology, National Institute of Cancer Research and Hospital, Mohakhali, Dhaka, \\ Bangladesh \\ ${ }^{2}$ Student, Department of Environmental Scienc, Jahangirnagar University (JU), Savar, Bangladesh
}

DOI: $10.36347 /$ sasjm.2021.v07i03.002

| Received: 23.02.2021 | Accepted: 05.03.2021 | Published: 21.03.2021

*Corresponding author: Dr. Taslima Nigar

Abstract

Original Research Article

Introduction: Cervical cancer is one of the major NCDs around the world and is the second leading malignancy in terms of mortality and incident cases in Bangladesh. The high mortality rate was associated with a lack of awareness regarding cervical cancer. The study was conducted to find out the awareness levels of cervical cancer, its symptoms, risk factors, detection methods, and barriers faced in screening. The aim of the study was to assess knowledge on factors associated with Cervical Cancer in women in Dhaka, Bangladesh. Methods: This was a cross-sectional study conducted over a 4-month time period with a sample size of 100 . The study was conducted with only female subjects in Dhaka city, among the patients coming to the Genealogical Department of the NICRH. Result: Maximum patients were above 45 years in age. $60 \%$ of the patients had no proper education. The majority of the patients were using birth control pills, and only 30 never used any OCP. $60 \%$ of patients were aware of cervical cancer, 40 were unaware. 84 of the patients were passive smokers. More than half of the patients had no knowledge of symptoms of cervical cancer. In regards to risk factors of cervical cancer, $70 \%$ were not sure if HPV infection was a risk factor for cervical cancer. Conclusion: The study showed surprisingly little knowledge of cervical cancer, its symptoms, risk factors, and screening methods. Awareness was positively related to education level.

Keywords: Cancer, Cervical Cancer, Demographic, HPV, Screening, Cancer Screening, Risk factors.

Copyright $\odot 2021$ The Author(s): This is an open-access article distributed under the terms of the Creative Commons Attribution 4.0 International License (CC BY-NC 4.0) which permits unrestricted use, distribution, and reproduction in any medium for non-commercial use provided the original author and source are credited.

\section{INTRODUCTION}

Bangladesh is one of the densely populated places in the world, and as a result of accelerated economic growth, many new diseases are emerging along with lifestyle changes. Cancer is one of the major Non-Communicable Diseases around the world. According to recent studies, the incidence of cancer has been increasing steeply, especially in counties with lower and middle incomes [1, 2]. Cervical cancer accounts for almost $12 \%$ of all female cancers worldwide. In Bangladesh alone, cervical cancer is the second leading malignancy in terms of both incidence and mortality among women, with an estimated 11,956 incident cases in 2012 [3]. This sort of high mortality rate has been attributed to lack of awareness, lack of organized screening, and overall poor health systems.[4] Cervical cancer is generally caused by the HPV virus, but most strains other than type-16 and type-18 are generally harmless.[5] Other co-factors in conjunction with generating the risk of transition from cervical HPV infection to cervical malignancy.[6] Early
Screening is a universally accepted method for detecting any form of cancer [7], but developing and under-developed countries still can't have regular screening due to various factors. Several studies have found that women with high screening rates have a high level of education. However, it is not a certainty that women with high education will always seek screening. Rates of screening are substantially lower in younger women aged 20-29 years and elderly women aged 60 years and above [8]. Women's knowledge of cervical cancer is one of the major factors on whether they'll go for a cancer screening [9]. Cultural Barriers also play a role in demotivating women from getting cervical cancer screening taken, as it involves exposure of private body parts [10]. A major factor in the lack of awareness of cervical cancer and its symptoms is often because cervical cancer rarely shows any signs at the early stages. And as the cancer progresses to more advanced stages, some of the symptoms that appear can mimic other infections. This results in patients receiving the wrong treatments at the hands of general 
practitioners. These factors, coupled with poverty, ignorance and lack of nearby services greatly impact cervical cancer prevention and management [11]. The risk factors in cervical cancer are many, but the most apparent one is the HPV virus. But a major risk factor, especially for developing countries like ours, is poverty, as poor women don't have access to proper medical services, and as a result, many diseases like cervical cancer remain undiagnosed for a long time. The lack of proper nutrition also plays a role as poor nutrition increases the risk for not only cervical cancer, but many other types of cancer as well [12]. Poverty can lead to some of the other risk factors like poor eating habits and weakened immune habits, which also increases the risk of cervical cancer [13, 14] Some studies have linked birth control pills to increased risk of cervical cancer [15]. As cervical cancer is on the global NCD watchlist, it comes with some common complications. The most common complications are infertility and side effects from treatment.

\section{OBJECTIVE}

To Assess Knowledge about Factors Associated with Cervical Cancer in Women in Bangladesh

\section{METHODOLOGY AND MATERIALS}

The study was conducted in Dhaka city, among the patients coming to the Genealogical Department of the National Institute of Cancer Research \& Hospital (NICRH). The study was conducted over a period of 4 months, among 100 willing patients. The patients were made aware of the study and proper consent was taken. A questionnaire was coded before entering the data into the computer by the researcher. The sample was selected conveniently to interview the study population considering the inclusion and exclusion criteria. The sample size was selected purposively. The statistical analysis of the data was carried out by using the software program SPSS. Data were being checked, edited, and appropriately coded before analysis. For summarizing data, statistics such as mean, median, and mode, and the percentage were calculated. The data were presented in tables, graphs, and charts.

\section{Inclusion Criteria}

- Only the female population

- Patients who had given consent to participate in the study.

- Those already diagnosed with cancer

\section{Exclusion Criteria}

- Mentally ill.

- Unable to answer the criteria question.

- Exclude those affected with other chronic diseases etc.

\section{RESULTS}

This was a cross-sectional observational study that was conducted to measure the awareness of cervical cancer symptoms and their risk factors among the female population of Bangladesh. The study was conducted in Dhaka city, among the patients coming to the Genealogical Department of the National Institute of Cancer The complete study was conducted with 100 female participants. Maximum patients were from the age group of 46-50, and the minimum patients were from the age group of 35-40 years. $60 \%$ of the patients had no proper education, and the remaining 40 had varying levels of education. The majority of the patients were using birth control pills, 38\% regularly, 32\% irregularly, and only 30 never used any OCP. $60 \%$ of patients were aware of cervical cancer, 40 were unaware. 84 of the patients were passive smokers, and the rest had no relation to smoking. When asked about various symptoms of cervical cancer, like vaginal bleeding between periods, persistent lower back pain, pain during sex, and some other symptoms, the majority of the patients had no knowledge if those were symptoms of cervical cancer or not. More than half were of this category. Of the remaining, $10-13 \%$ disagreed that these were signs or symptoms of cervical cancer, and the remaining acknowledged that these symptoms were of cervical cancer. Only 24\% agreed that consistent lower back pain was a symptom associated with cervical cancer, $13 \%$ disagreed and 63 were unsure. In regards to risk factors of cervical cancer, $70 \%$ were not sure if HPV infection was a risk factor for cervical cancer. $\%$ agreed and $6 \%$ disagreed. Another major risk factor was smoking, but $52 \%$ were unsure about this as a risk for cervical cancer, 34\% agreed and 14\% disagreed. Only 13\% agreed that having an uncircumcised sex partner was a risk factor, $20 \%$ disagreed with this statement and $67 \%$ had no idea regarding this. Only $10 \%$ recognized having too many babies as a risk factor, $31 \%$ disagreed and $59 \%$ were not sure of this statement. Awareness regarding cervical cancer screening was present only in $30 \%$, and $70 \%$ were unaware. The most apparent barrier faced against cervical cancer screening was little understanding of cervical cancer, as $70 \%$ fall into this category. $60 \%$ didn't know where to go for cervical cancer screening, $54 \%$ faced opposition from their husband, 53\% were not suggested for screening by health care workers, and $50 \%$ of the patients did not think they were at risk.

Table-1: Distribution of study subjects by age $(\mathbf{N}=\mathbf{1 0 0})$

\begin{tabular}{|l|l|l|}
\hline \multicolumn{2}{|c|}{ Cancer patient (100) } \\
\hline Age group (years) & Frequency & Percentage (\%) \\
\hline $35-40$ & 16 & 16 \\
\hline $41-45$ & 26 & 26 \\
\hline $46-50$ & 36 & 36 \\
\hline $51-55$ & 22 & 22 \\
\hline Total & $\mathbf{1 0 0}$ & $\mathbf{1 0 0}$ \\
\hline
\end{tabular}


Taslima Nigar \& Monirul Hassan., SAS J Med, Mar, 2021; 7(3): 67-72

Table 1 shows the distribution of study subjects by age. Among 100 cancer patients, maximum $(36 \%)$ patients were in the age group 46-50 years followed by $(26 \%)$ and $(22 \%)$ patients were in the age group 41 - 45 years and 51-55 years respectively

Table-2: Distribution of study subjects by education (N=100)

\begin{tabular}{|l|l|l|}
\hline & \multicolumn{2}{|l|}{ Cancer patient $(\mathbf{N}=100)$} \\
\hline Education level & Frequency & Percentage \\
\hline No education & 60 & 60 \\
\hline$\leq$ primary & 16 & 16 \\
\hline$\geq$ SSC & 14 & 14 \\
\hline$>$ SSC & 10 & 10 \\
\hline Total & $\mathbf{1 0 0}$ & $\mathbf{1 0 0}$ \\
\hline
\end{tabular}

In the cancer group, $60 \%$ of women were noneducated and educational level up to primary were $(16 \%)$. About (14\%) cancer patients had education above primary level but below SSC level. An educational level above SSC is found in $10 \%$ of cancer patients.

Table-3: Distribution of study population by use of oral contraceptive $(\mathrm{N}=100)$

\begin{tabular}{|l|l|l|}
\hline & Cervical cancer $(\mathbf{N}=100)$ \\
\hline OCP use & Frequency & Percentage \\
\hline Regular & 38 & 38 \\
\hline Irregular & 32 & 32 \\
\hline Never & 30 & 30 \\
\hline Total & $\mathbf{1 0 0}$ & $\mathbf{1 0 0}$ \\
\hline
\end{tabular}

In the study group, $38 \%$ were regularly using oral contraceptive pill, $32 \%$ were Irregular users and $30 \%$ never used any birth control pill.

Table-4: Distribution of study population by smoking $(\mathbf{N}=\mathbf{1 0 0})$

\begin{tabular}{|l|l|l|}
\hline \multirow{2}{*}{ Smoking Status } & \multicolumn{2}{|l|}{ Cervical cancer $(\mathbf{N}=100)$} \\
\cline { 2 - 3 } & Frequency & Percentage \\
\hline Smoker & 0 & 0 \\
\hline No passive Smoker & 16 & 16 \\
\hline Passive smoker & 84 & 84 \\
\hline Total & $\mathbf{1 0 0}$ & $\mathbf{1 0 0}$ \\
\hline
\end{tabular}

The study found no active smokers, but $84 \%$ were passive smokers and $16 \%$ were not passive smokers.

\section{Knowledge of cervical cancer}

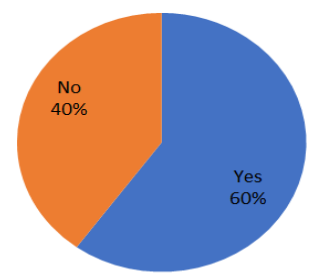

Fig-1: Knowledge of cervical cancer among the respondents

The Majority of the respondent's 60\% $(n=60)$ had heard of cervical cancer, whereas $40 \%(n=40)$ had never heard of cervical cancer.

Table-5: Respondent's knowledge of signs and symptoms of cervical cancer

\begin{tabular}{|c|c|c|c|c|c|}
\hline $\begin{array}{l}\text { Knowledge of signs of cervical } \\
\text { cancer }\end{array}$ & Not Sure & Disagree & $\begin{array}{l}\text { Strongly } \\
\text { Disagree }\end{array}$ & Agree & $\begin{array}{l}\text { Strongly } \\
\text { Agree }\end{array}$ \\
\hline Vaginal bleeding between periods & $58 \%(\mathrm{n}=58)$ & $11 \%(n=11)$ & & $\begin{array}{l}31 \% \\
(n=31)\end{array}$ & \\
\hline Persistent lower back pain & $63 \%(n=63)$ & $13 \%(n=33)$ & & $\begin{array}{l}24 \% \\
(\mathrm{n}=24)\end{array}$ & \\
\hline $\begin{array}{l}\text { Persistent vaginal discharge with } \\
\text { unpleasant Smell }\end{array}$ & $58 \%(\mathrm{n}=58)$ & $10 \%(n=10)$ & & $\begin{array}{l}32 \% \\
(\mathrm{n}=32)\end{array}$ & \\
\hline Discomfort or pain during sex & $65 \%(n=65)$ & $10 \%(n=10)$ & & $\begin{array}{l}25 \% \\
(\mathrm{n}=25)\end{array}$ & \\
\hline Vaginal bleeding after menopause & $62 \%(\mathrm{n}=62)$ & $\begin{array}{l}4 \% \\
(n=4)\end{array}$ & & $\begin{array}{l}34 \% \\
(n=34)\end{array}$ & \\
\hline Vaginal bleeding during or after sex & $58 \%(\mathrm{n}=58)$ & $10 \%$ & & $\begin{array}{l}32 \%(\mathrm{n}= \\
32)\end{array}$ & \\
\hline
\end{tabular}

Among the respondents, $31 \%$ identified bleeding between menstrual periods as a sign of cervical cancer. A slightly higher proportion, 32\% identified the presence of smelly vaginal discharge as a symptom of cervical cancer. Similarly, 34\% and $32 \%$ identified vaginal bleeding after menopause and bleeding during or after sex respectively as symptoms of cervical cancer. About 24\% and 25\% of respondents identified pain during sex and lower back pain as signs of cervical cancer respectively. 
Taslima Nigar \& Monirul Hassan., SAS J Med, Mar, 2021; 7(3): 67-72

Table-6: Risk factors for cervical cancer

\begin{tabular}{|l|l|l|l|l|l|}
\hline Risk factors of cervical cancer & $\begin{array}{l}\text { Strongly } \\
\text { Disagree }\end{array}$ & Disagree & Not sure & Agree & $\begin{array}{l}\text { Strongly } \\
\text { Agree }\end{array}$ \\
\hline Infection with HPV & & $6 \%(\mathrm{n}=6)$ & $70 \%(\mathrm{n}=70)$ & $\mathbf{2 4 \%}(\mathrm{n}=24)$ & \\
\hline Smoking cigarettes & & $14 \%(\mathrm{n}=14)$ & $52 \%(\mathrm{n}=52)$ & $\mathbf{3 4 .} \%(\mathrm{n}=34)$ & \\
\hline Long-term use of contraceptives & & $10 \%(\mathrm{n}=10)$ & $49 \%(\mathrm{n}=49)$ & $\mathbf{4 1} \%(\mathrm{n}=41)$ & \\
\hline Having STI's & & $9 \%(\mathrm{n}=9)$ & $54 \%(\mathrm{n}=54)$ & $\mathbf{3 7 \%}(\mathrm{n}=37)$ & \\
\hline Having an uncircumcised sexual partner & & $20 \%(\mathrm{n}=20)$ & $67 \%(\mathrm{n}=67)$ & $\mathbf{1 3} \%(\mathrm{n}=13)$ & \\
\hline Having sex at an early age & & $15 \%(\mathrm{n}=15)$ & $60 \%(\mathrm{n}=60)$ & $\mathbf{2 5} \%(\mathrm{n}=25)$ & \\
\hline Having multiple sexual partners & & $11 \%(\mathrm{n}=11)$ & $52 \%(\mathrm{n}=52)$ & $\mathbf{3 7 \%}(\mathrm{n}=37)$ & \\
\hline Having many children & & $31 \%(\mathrm{n}=31)$ & $59 \%(\mathrm{n}=59)$ & $\mathbf{1 0} \%(\mathrm{n}=10)$ & \\
\hline $\begin{array}{l}\text { Having a sexual partner with multiple } \\
\text { partners }\end{array}$ & $13 \%(\mathrm{n}=13)$ & $54 \%(\mathrm{n}=54)$ & $\mathbf{3 3} \%(\mathrm{n}=33)$ & \\
\hline
\end{tabular}

Only 24\% were aware that infection with Human Papillomavirus (HPV) is a risk factor associated with cervical cancer. In addition, $34 \%$ of the respondents identified cigarette smoking as a risk. The majority of the respondents $41 \%$ identified the longterm use of the oral contraceptive pill as a risk factor. Other risk factors identified by the respondents included: presence or history of sexually transmitted infections $37 \%$, having an uncircumcised partner $13 \%$, early sexual debut $25 \%$, and having many sexual partners $37 \%$. On the other hand, $31 \%$ disagreed to acknowledge having too many children as a risk factor.

\section{DISCUSSION}

Bangladesh is one of the most densely populated countries in the world. Ever since poverty has started to decline in the early 2000s, many economic development and lifestyle changes have occurred. The occurrence of cancer is one of the bands that came with the goods. Cancer is one of the NCD and is under observation to help reduce the mortality rate by NCD by $25 \%$ by 2025 . It is the fourth most common female cancer worldwide. In 2012 alone, 528,000 new cases occurred and 266,000 deaths were caused by cervical cancer. Cervical cancer has become one of the major causes of cancer death in the world, and around $87 \%$ of these occur in developing countries like ours. Just in Bangladesh alone, cervical cancer is the second leading malignancy for both incidence and mortality among women, with an estimated 11,956 incident cases and 6582 deaths in 2012 [3]. Several factors including lack of knowledge, lack of high-quality cervical cancer screening and treatment programs are responsible for such high mortality rates [4]. The most common cause of cervical cancer is the HPV Virus. The link between HPV infection and cervical cancer was discovered in the early 1980s and became well established in 1996 [5, $16,17]$ Mostly the type-16 and type- 18 are responsible for cervical cancer, and the other variants are generally harmless and clear spontaneously. The use of vaccines has been effective against HPV types 16 and 18, and also low-risk variants like type 11 and 6. Unfortunately, these vaccines are expensive and hard to come by in low-income countries [18]. The world health organization recommends proper screening as a preventative measure against cervical cancer. One of the screening methods is the Pap scrape smear technique, which detects pre-cancerous lesions in the uterine cervix [19]. Unfortunately, pap smear screening has been difficult to conduct in many developing countries because of the need for cytotechnologists, tracking of multiple screening visits, and specialized equipment. Cervical cancer has many risk factors, but the major risk factor, especially for low-income countries like ours, is poverty. Because of the poor financial situation, many women don't have access to proper medical services. This results in many diseases like cervical cancer remain undiagnosed for a long time. Poverty also leads to a lack of proper nutrition, which increases the risk of cervical cancer by several times $[13,14]$. Distributing the patients by their age group, the majority of the patients were above the age of 45 , as 36 patients belonged to the age group of 46-50, and 22 belonged to the group of 51-55 years. The youngest age group (35-40) had only 16 cases of cervical cancer. This provides valuable information that age increases the risk of cervical cancer. On the other hand, this can also mean that the younger female population in our country is less likely to go for cervical cancer screening, and as a result, the diagnosis comes much later in their lives. Looking at the educational status of the study group, it was found that $60 \%$ of women did not receive any primary education. Educational level up to primary was present in $16 \%$. About $14 \%$ of cancer patients had education above primary level but below SSC level. An educational level above SSC was found in only $10 \%$ of cancer patients. Basic knowledge of cervical cancer was present in $60 \%$ of the cases, but the remaining $40 \%$ had no idea about cervical cancer. Those who received higher levels of educations were among the $60 \%$ who were aware of cervical cancer. This shows the importance of education in awareness regarding any sort of disease, not only cervical cancer. Overuse of birth control pills has been linked to an increased risk of cervical cancer in some previous studies [20, 21]. In our study, $38 \%$ were regularly using oral contraceptive pills, 32\% were Irregular users, and $30 \%$ never used any birth control pill. These findings are comparable to the findings from other studies. Smoking is also considered a major risk factor for cancer. In our study, although we did not find any active smokers, $84 \%$ were passive smokers, and only $16 \%$ were not passive 
smokers. It can be assumed that having only female study samples contributed to finding no active smokers among the study subjects. When asked about various signs and symptoms of cervical cancer, the results were the following. $31 \%$ identified bleeding between menstrual periods as a sign of cervical cancer. A slightly higher proportion, $32 \%$ identified the presence of smelly vaginal discharge as a symptom of cervical cancer. Similarly, 34\% identified vaginal bleeding after menopause and $32 \%$ identified bleeding during or after sex as symptoms of cervical cancer. About $24 \%$ identified pain during sex and $25 \%$ of respondents identified lower back pain as signs of cervical cancer. The majority of the respondents were unsure about most of the symptoms of cervical cancer, as $65 \%$ were unsure whether discomfort or pain during sex was a sign of cervical cancer. $63 \%$ could not associate consistent lower back pain with cervical cancer, and $62 \%$ were unsure whether vaginal bleeding after menopause was a sign of cervical cancer. This may be influenced by the fact that most of these symptoms are related to sexual intercourse and women's private parts, and as such, is not generally discussed among others. Proper knowledge about the risk factors of cervical cancer was shockingly scarce, as showed in the gathered data. Long-term use of birth pills was recognized as a risk factor by $41 \%, 49 \%$ were unsure and $10 \%$ disagreed with this fact. $37 \%$ acknowledged both having STI's and having multiple sexual partners as a risk factor. One of the major risk factors is infection with HPV, but only $24 \%$ of participants acknowledged this as a risk factor, $6 \%$ disagreed and the remaining 70 were completely unsure regarding this. Similarly, with smoking, only $34 \%$ recognized this as a risk factor, 14\% disagreed and 52 were unsure. The biggest disagreement, however, was whether having many children was a risk factor, as $31 \%$ did not recognize this as a proper risk, $59 \%$ were unsure and only 10 participants recognized this as a risk factor. The proper way to determine cervical cancer is through screening, but Bangladeshi women faced many barriers in screening. The majority of this was little to no knowledge or understanding of cervical cancer. Next was not knowing where to go for screening, and then a lack of approval from their marital partner. Some other barriers were also faced in cervical cancer screening. This study provided insight into our society regarding knowledge of diseases, risk factors, and symptoms.

\section{Limitations of the study}

The study was conducted in a short time period with a small sample size. SO, the result may not reflect the scenarios of the whole country/

\section{CONCLUSION}

The results showed surprisingly little knowledge of cervical cancer, its symptoms, risk factors, and screening methods. Awareness was positively related to education level.

\section{RECOMMENDATION}

The study needs to be conducted with a larger sample size time period. For proper and accurate results, the study should be conducted over multiple medical institutes.

\section{REFERENCES}

1. Fitzmaurice C, Dicker D, Pain A, Hamavid H, Moradi-Lakeh M, MacIntyre MF, Allen C, Hansen G, Woodbrook R, Wolfe C, Hamadeh RR. The global burden of cancer 2013. JAMA oncology. 2015 Jul 1; 1(4):505-27.

2. Global Burden of Disease Cancer Collaboration. The global burden of cancer 2013. JAMA oncology. 2015 Jul 1; 1(4):505.

3. International Agency for Research on Cancer. GLOBOCAN 2012: Estimated cancer incidence, mortality and prevalence worldwide in 2012. IARC CancerBase.

4. Denny L. The prevention of cervical cancer in developing countries. BJOG: An International Journal of Obstetrics \& Gynaecology. 2005 Sep 1; 112(9):1204-12.

5. Dürst M, Gissmann L, Ikenberg H, Zur Hausen H. A papillomavirus DNA from a cervical carcinoma and its prevalence in cancer biopsy samples from different geographic regions. Proceedings of the National Academy of Sciences. 1983 Jun 1; 80(12):3812-5.

6. Holowaty P, Miller AB, Rohan T, To T. Natural history of dysplasia of the uterine cervix. Journal of the National Cancer Institute. 1999 Feb 3; 91(3):252-8.

7. Adjorlolo-Johnson G, Unger ER, Boni-Ouattara E, Touré-Coulibaly K, Maurice C, Vernon SD, Sissoko M, Greenberg AE, Wiktor SZ, Chorba TL. Assessing the relationship between HIV infection and cervical cancer in Cote d'Ivoire: a case-control study. BMC infectious diseases. 2010 Dec; 10(1):1-8.

8. Singh KK, Bloom SS, Tsui AO. Husbands' reproductive health knowledge, attitudes, and behavior in Uttar Pradesh, India. Studies in family planning. 1998 Dec 1:388-99.

9. Liao CC, Wang HY, Lin RS, Hsieh CY, Sung FC. Addressing Taiwan's high incidence of cervical cancer: factors associated with the Nation's low compliance with Papanicolaou screening in Taiwan. Public health. 2006 Dec 1; 120(12):11706.

10. Lyimo FS, Beran TN. Demographic, knowledge, attitudinal, and accessibility factors associated with uptake of cervical cancer screening among women in a rural district of Tanzania: three public policy implications. BMC public health. 2012 Dec; 12(1):1-8.

11. Gillet E, Meys JF, Verstraelen H, Verhelst R, De Sutter P, Temmerman M, Broeck DV. Association between bacterial vaginosis and cervical 
Taslima Nigar \& Monirul Hassan., SAS J Med, Mar, 2021; 7(3): 67-72

intraepithelial neoplasia: systematic review and meta-analysis. PloS one. 2012 Oct 2;7(10):e45201.

12. Palacio-Mejía LS, Rangel-Gómez G, HernándezAvila M, Lazcano-Ponce E. Cervical cancer, a disease of poverty: mortality differences between urban and rural areas in Mexico. Salud pública de méxico. 2003; 45:315-25.

13. Barchitta M, Maugeri A, Quattrocchi A, Agrifoglio O, Scalisi A, Agodi A. The association of dietary patterns with high-risk human papillomavirus infection and cervical cancer: a cross-sectional study in Italy. Nutrients. 2018 Apr; 10(4):469.

14. Mora-García ML, Monroy-García A. Immune response in cervical cancer. Strategies for the development of therapeutic vaccines. Revista Médica del Instituto Mexicano del Seguro Social. 2015; 53:S206.

15. Hellberg D. Sex steroids and cervical cancer. Anticancer research. 2012 Aug 1; 32(8):3045-54.

16. National Institutes of Health (US). Office of Medical Applications of Research. NIH consensus statement. National Institutes of Health, Office of Medical Applications of Research; 1996.

17. Burd EM. Human papillomavirus and cervical cancer. Clinical microbiology reviews. 2003 Jan 1; 16(1):1-7.

18. Elfström KM, Herweijer E, Sundström K, Arnheim-Dahlström L. Current cervical cancer prevention strategies including cervical screening and prophylactic human papillomavirus vaccination: a review. Current opinion in oncology. 2014 Jan 1; 26(1):120-9.

19. Mendes D, Mesher D, Pista A, Baguelin M, Jit M. Understanding differences in cervical cancer incidence in Western Europe: comparing Portugal and England. The European Journal of Public Health. 2018 Apr 1; 28(2):343-7.

20. Sreedevi A, Javed R, Dinesh A. Epidemiology of cervical cancer with special focus on India. International journal of women's health. 2015; 7:405.

21. Thapa N, Maharjan M, Petrini MA, Shah R, Shah S, Maharjan N, Shrestha N, Cai H. Knowledge, attitude, practice and barriers of cervical cancer screening among women living in mid-western rural, Nepal. Journal of gynecologic oncology. 2018 Jul; 29(4). 